\title{
Are direct messages (texts and emails) from wagering operators associated with betting intention and behavior? An ecological momentary assessment study
}

\author{
ALEX M. T. RUSSELL ${ }^{1 *}$, NERILEE HING ${ }^{2}$, MATTHEW BROWNE ${ }^{2}$ and VIJAY RAWAT ${ }^{3}$ \\ ${ }^{1}$ Experimental Gambling Research Laboratory, School of Health, Medical and Applied Sciences, CQUniversity, Sydney, NSW, Australia \\ ${ }^{2}$ Experimental Gambling Research Laboratory, School of Health, Medical and Applied Sciences, CQUniversity, Bundaberg, QLD, Australia \\ ${ }^{3}$ Experimental Gambling Research Laboratory, School of Health, Medical and Applied Sciences, CQUniversity, Melbourne, VIC, Australia
}

(Received: August 14, 2018; revised manuscript received: August 31, 2018; accepted: September 2, 2018)

\begin{abstract}
Background and aims: Direct messaging via text messages (texts) and emails is a widely used method to advertise sports and race-betting offers. However, they have attracted little research, as this advertising is not in the public domain. This study aimed to determine whether betting expenditure is related to receiving direct wagering messages, and the specific inducements they promote. We hypothesized that receiving direct messages, particularly texts, would be related to betting expenditure within $24 \mathrm{hr}$. Methods: In this ecological momentary assessment study, regular sports $(n=98)$ and race $(n=104)$ bettors from Australia completed short daily surveys over 1 week that captured exposure to direct messages, betting behavior in the previous $24 \mathrm{hr}$, and betting intention for the next $24 \mathrm{hr}$. Respondents were asked to forward any texts and emails received to the researchers, who coded them for inducement content. Results: Longitudinal analyses found that receiving emails was positively associated with betting intention, whereas texts were positively associated with higher likelihood of betting and betting expenditure. These effects persisted when controlling for problem gambling status and signature betting events. Refund stake and bonus odds inducements were positively associated with likelihood of race betting (although not in multivariate models), as were bonus winnings inducements for sports betting. Discussion and conclusions: Direct messages, particularly texts, are powerful marketing tools, encouraging a nearly immediate, and arguably impulsive, betting response, which may increase gambling-related problems. Overseeing this private form of advertising presents challenges to regulators, and to public health efforts that aim to reduce gambling harm.
\end{abstract}

Keywords: direct messages, wagering, advertising, inducements, gambling, intention

\section{INTRODUCTION}

Gambling is a popular pastime in Australia. Per capita, Australians lose more money than residents of any other country (H2 Gambling Capital, 2017). The most popular forms are lottery-type games, electronic gaming machines, race wagering, and sports betting (Hing, Gainsbury, et al., 2014). Sports betting and race wagering are the only forms where expenditure is increasing (Queensland Government Statisticians Office, 2017).

Sports and race betting can legally be provided by Australian-licensed operators at the sports ground or race track, at land-based venues (hotels, clubs, and casinos), and via the telephone or Internet. The convenience of betting online is driving increased participation in these forms (Gainsbury, 2012; Hing, Russell, Vitartas, \& Lamont, 2016; Sproston, Hanley, Brook, Hing, \& Gainsbury, 2015), and more Australians are betting via the Internet, from $15.7 \%$ in 2011 to $34 \%$ in 2018 (Roy Morgan, 2018). This has led to intense competition among Australian-based online wagering operators, as indicated by an abundance of wagering advertising and inducements (Hing, Russell, Rockloff, et al., 2018), which have been contentious
(Australian Communication and Media Authority, 2013), and the subject of several government inquiries (Department of Broadband, Communications and the Digital Economy, 2013; Joint Select Committee on Gambling Reform, 2011, 2013; O'Farrell, 2015). Sports betting advertising has been linked to problem gambling (Lopez-Gonzalez, Estévez, \& Griffiths, 2017, 2018; Lopez-Gonzalez, Guerrero-Solé, \& Griffiths, 2018), and is recalled in detail by children, prompting concerns around normalization (Pitt, Thomas, Bestman, Daube, \& Derevensky, 2017).

Inducements (e.g., offers to match deposits with bonus bets) are common in wagering advertising (Guerrero-Solé, Lopez-Gonzalez, \& Griffiths, 2017; Hing, Sproston, Brading, \& Brook, 2015; Lopez-Gonzalez \& Griffiths, 2017). A recent Australian study found that wagering inducements influence betting expenditure, including

\footnotetext{
* Corresponding author: Dr. Alex M. T. Russell, BSc (Psych), GradDipSci (Merit, Psych), PhD; Experimental Gambling Research Laboratory, School of Health, Medical and Applied Sciences, CQUniversity, Level 6, 400 Kent St., Sydney, NSW 2000, Australia; Phone: +61 29324 5026; E-mail: a.m.russell@ cqu.edu.au
}

This is an open-access article distributed under the terms of the Creative Commons Attribution-NonCommercial 4.0 International License, which permits unrestricted use, distribution, and reproduction in any medium for non-commercial purposes, provided the original author and source are credited, a link to the CC License is provided, and changes - if any - are indicated. 
betting when not intending to, and betting more than intended (Hing, Russell, Rockloff, et al., 2018). That study found that direct messages to consumers via text messages (texts or SMS), email, or telephone calls had the most influence on betting behavior. This study aims to examine the effects of these messages on betting in more detail.

\section{Direct messages}

Direct messages are sent directly to consumers, through texts, emails, or telephone calls using betting account details. This allows operators to track behavior, and target consumers who may be most receptive to inducements (Scharl, Dickinger, \& Murphy, 2005; Shankar \& Balasubramanian, 2009) or target lapsed consumers (Hing, Cherney, Blaszczynski, Gainsbury, \& Lubman, 2014).

Direct messages are conveyed privately, in contrast to advertising in public mass media. This distinction is crucial in Australia's most populated state, where it is illegal for operators to advertise gambling inducements in public (New South Wales Department of Industry: Liquor and Gaming [NSW DILG], 2015). The definition of "public" in this context excludes direct messaging sent to existing account holders (NSW DILG, 2016, 2018). Thus, direct messaging has become an increasingly important advertising mechanism for Australian wagering operators. Their private nature means that fewer people see them, likely resulting in fewer complaints, as well as making it difficult for regulators to access them.

In general, direct messaging is a particularly effective form of advertising (Drossos, Giaglis, Vlachos, Zamani, \& Lekakos, 2013; Hing, Russell, Rockloff, et al., 2018). Marketers are increasingly using texts in favor of email, partly due to the high prevalence of smartphone ownership (88\% in Australia; Deloitte, 2017), allowing consumers to receive these messages almost immediately. Text message marketing is highly effective compared to emails. Unsolicited contact (spam) is far more prevalent for emails (90\%) than for texts (1\%; Doherty, 2014), and consumers pay less attention to emails due to spam (Fallows, 2003). Consumers are far more likely to open texts (94\% open rate; Lam, 2018) than emails (25\% open rate; Chaffey, 2018), and to respond or take up an offer more quickly (within $90 \mathrm{~s}$ on average), compared to 2.5 days for emails (Davey, 2013). These factors may explain why texts are a particularly effective advertising medium (Scharl et al., 2005; Shankar \& Balasubramanian, 2009). Nonetheless, both texts and emails are received on smartphones, which consumers can also use to place bets; therefore, both of these direct channels are likely to be effective advertising media.

\section{Link with impulse betting and problem gambling}

Because smartphone texts allow for immediate action, texts promoting wagering may encourage impulse betting, which has been linked to problem gambling (Flack \& Buckby, 2018; Hing, Li, Vitartas, \& Russell, 2018; Russell, Hing, Li, \& Vitartas, 2018; Yan, Zhang, Lan, Li, \& Sui, 2016). Because people with gambling problems tend to be more impulsive (Russell et al., 2018), they may be more likely to respond to wagering inducements promoted via texts, leading to excessive expenditure.
A key question is whether direct messages have an effect on gambling behavior. This study aimed to determine whether betting expenditure is related to receiving direct messages delivered via email and/or text, and to determine which specific types of inducements delivered via direct message may be most influential. We hypothesized that gambling expenditure would be associated with direct messages, particularly texts.

\section{METHODS}

\section{Respondents}

The sample for this study consists of 98 sports bettors and 104 race bettors from Australia. All participants had taken part in a previous wagering study conducted by the researchers and had agreed to participate in future research (original study: Hing, Russell, Rockloff, et al., 2018). Respondents were recruited to the original study as regular (at least fortnightly) sports or race bettors, from two sources: account holders with a major Australian-licensed online wagering company, and a database of participants who had participated in previous research conducted by the first and second authors. The wagering company had no further involvement and no access to the data.

This previous study consisted of 15 ecological momentary assessment (EMA) surveys, whereby participants take part in short, regular assessments. We invited those who had completed at least 12 of those 15 EMAs, to maximize response rates. We also specifically invited all those scoring $8+$ on the Problem Gambling Severity Index (PGSI; Ferris \& Wynne, 2001), to ensure they were adequately represented in the sample. This led to 194 sports bettors and 218 race bettors being invited to participate.

Inclusion criteria were providing informed consent, aged $18+$, gambling at least fortnightly on sports or races in the past 12 months, and willingness to answer multiple short surveys during the study period. Sports bettors were also required to have bet on Australian Football League (AFL) or National Rugby League (NRL), as the study was conducted during the week of the grand finals of those competitions. We also asked respondents whether they were currently opted-in to receiving direct wagering messages and whether they intended to remain opted-in during the data collection period. Respondents who said "no" to either question were excluded.

Sample response rates, along with demographic and PGSI measures, are reported in Table 1. In terms of betting behavior, $96.9 \%$ of sports bettors bet on AFL in the past 12 months, and $78.6 \%$ on NRL. Among race bettors, $99.0 \%$ bet on horse racing, and $67.3 \%$ on greyhound racing.

\section{EMA procedure}

This study also utilized an EMA design. Respondents were sent a link to an online survey through text message each day for seven consecutive days, and reimbursed $\$ 7$ for each completed survey (possible maximum compensation of $\$ 49$, paid in electronic shopping vouchers). These invitations were sent at 4 p.m. each day, and respondents were allowed to 
Table 1. Response and eligibility rates and sample characteristics for sports and race bettors

\begin{tabular}{lcc}
\hline Measure & Sports bettors & Race bettors \\
\hline Response and eligibility rates & & 218 \\
Invited from original study & 194 & 113 \\
Responded to invitation & 111 & $51.8 \%$ of those invited \\
& $57.2 \%$ of those invited & 110 \\
Met inclusion criteria & 102 & $97.3 \%$ of those who responded \\
& $91.9 \%$ of those who responded & 104 \\
Responded to at least one EMA & 98 & $92.0 \%$ of those who responded \\
& $88.3 \%$ of those who responded & 94.2 \\
Sample characteristics & 92.9 & $44.7(12.4)$ \\
Gender (\% male) & $41.8(13.1)$ & $24-72$ \\
Age [mean (SD)] & $20-74$ & 21.2 \\
Age range (years) & 20.4 & 25.0 \\
PGSI: non-problem (\%) & 29.6 & 33.7 \\
PGSI: low risk (\%) & 36.7 & 20.2 \\
PGSI: moderate risk (\%) & 13.3 & \\
PGSI: problem gambler (\%) & & \\
\hline
\end{tabular}

Note. SD: standard deviation; EMA: ecological momentary assessment; PGSI: Problem Gambling Severity Index.

respond within $23 \mathrm{hr}$ to complete the survey. Sports bettors were surveyed from September 26 to October 2, 2017 (the week leading up to the NRL and AFL grand finals). Race bettors were surveyed from November 3 to 9, 2017, which was the week of the Melbourne Cup. The NRL and AFL grand finals and the Melbourne Cup are major betting events within Australia, and we expected advertising to be at peak levels during these time periods. Approximately, 65\% of each sample completed at least six of the seven EMAs.

The EMA methodology allows the behavior of interest to be assessed as it occurs, or close to when it occurs, reducing recall issues and increasing accuracy compared to regular surveys (Stone \& Shiffman, 1994). This design also allowed comparison of intended versus actual expenditure, using longitudinal analyses.

\section{Measures}

Respondents initially completed a baseline survey that determined eligibility and captured mobile phone number and email address (to send survey links and compensation), postcode, types of sports or races they had bet on, and frequency of betting on these, which Australian-based operators they have accounts with, how often they bet with each operator within the past 12 months, and the PGSI.

The daily EMA surveys captured the number of emails, texts, and/or phone calls the respondents had received from wagering operators in the previous $24 \mathrm{hr}$; actual sports or race-betting expenditure over the previous $24 \mathrm{hr}$; and intended sports or race-betting expenditure over the next $24 \mathrm{hr}$. Very few phone calls were received, so they were not included in analyses. Respondents were asked to forward all direct messages received to a mobile phone number (for texts), or an email address (for emails), which were monitored by the research team.

\section{Statistical analysis}

The research team coded the content of all texts and emails forwarded by respondents by date at which the message was received and type of inducement (if applicable, bonus winnings, refund stake, match stake/deposit, sign up, and bonus odds offers). Other inducements were also coded (e.g., refer a friend offers), but were not included in analyses due to their low frequency. This coding was conducted by one researcher, and verified by a second researcher, based on a preexisting classification of inducements (Hing et al., 2015). Each message was coded using an anonymous respondent ID, so the content could be linked to their EMA data, specifically intended and actual betting behavior.

We conducted longitudinal analyses on two dependent variables, intended betting expenditure and actual betting expenditure. Both variables were zero-inflated, so both were modeled in two-stage hurdle models: comparing those who reported $\$ 0$ versus $\$ 1+$ (i.e., those who did and did not intend to bet, and those who did and did not actually bet), and then, among those who intended to bet (or actually bet), how much they intended to bet (or actually bet). Each hurdle model was applied separately to sports and race betters, for intended and actual expenditure.

The independent variables (IVs) in the linear mixedeffects models were related to the direct messages. Initially, the total number of direct messages received was the IV. Then, we used the number of emails and texts received (channel) separately as IVs, followed by the number of each inducement (content).

All analyses were initially conducted as bivariate analyses. We then conducted multivariate models separately for direct message channel and content, to control for other possible explanatory factors: the respondent's problem gambling status (PGSI 8+) and whether or not the day was a signature betting day (Melbourne Cup, AFL grand final, and NRL grand final). For actual betting expenditure, we also examined controlling for intended expenditure (i.e., comparing intended spend in the next $24 \mathrm{hr}$ to reported actual spend in that $24 \mathrm{hr}$ ). For sports bettors, intention was not significantly associated with betting expenditure, whereas for race bettors, the association was negative, contrary to findings from a similar study (Hing, Russell, Rockloff, et al., 2018). Therefore, we did not control for intention in 
subsequent analyses. We also explored interactions with problem gambling status, for both direct messaging channel and content, and for intended and actual betting expenditure, none of which were statistically significant.

The $\$ 1+$ components of intention and betting expenditure were right-skewed, and thus the natural logarithm of each was taken prior to analysis. We used the lme4 package (Bates, Mächler, Bolker, \& Walker, 2015) in R software (R Core Team, 2017); the glmer function for 0 versus 1+ dependent variables, and the lmer function for expenditure (log dollar value) when respondents reported betting. Both random effects (individual ID) and fixed effects (all other variables) were specified. The unit of analysis was each day for each bettor.

\section{Ethics}

All participants gave informed consent and were informed they could withdraw at any time. Data were anonymized before analysis. The study was approved by Human Research Ethics Committee of CQUniversity Australia, clearance numbers H16/06-178 and H16/08-234.

\section{RESULTS}

\section{Content of messages received}

Over the course of 7 days, the 98 sports bettors reported receiving 364 emails and 228 texts, an average of 3.7 $(S D=3.5)$ and $2.3(S D=2.6)$ per respondent, respectively. The 104 race bettors reported receiving 671 emails and 442 texts, an average of $6.5(S D=6.8)$ and $4.3(S D=4.9)$ per respondent, respectively. Sports bettors forwarded 98 emails and 111 texts to the research team $(26.9 \%$ and $48.7 \%$, respectively), whereas the race bettors forwarded 481 emails and 241 texts $(71.7 \%$ and $54.5 \%$, respectively). Most messages were related to the AFL or NRL grand finals for sports bettors, and the Melbourne Cup for race bettors.

Texts were generally text-only, with no images. Some texts included a link to a webpage where respondents could take up a promotion, whereas others functioned as advertising. For example "Get $\$ 2$ for Dustin Martin to win the Brownlow Medal by 2+ votes (max \$20) AND we're giving you the chance to create your own Brownlow Medal betting markets! Use \#BrownlowCYO on Twitter to submit your market." In contrast, emails contained more rich information, images, and often more than one offer or inducement.

Some types of inducements were not sufficiently prevalent to be included in analyses. Those included were refund stake offers, match stake/deposit offers, bonus winnings, and (for sports bettors only) sign-up offers and bonus odds offers.

\section{Expenditure and intention to spend}

Intention and actual betting behavior varied by day. For example, on the day after the grand finals, only $15.2 \%$ of sports bettors intended to bet, whereas approximately $90 \%$ of each group reported intending to bet on the Melbourne Cup or grand finals. Median intended expenditure on any day ranged $\$ 40-\$ 110$ for race bettors, and $\$ 20-\$ 50$ for sports bettors, and median actual expenditure ranged $\$ 40-\$ 116$ for race bettors and $\$ 20-\$ 50$ for sports bettors.

\section{The relationship between direct messages and intended betting}

Tables 2 and 3 present results for betting intention. For both groups, those who received more direct messages, regardless of channel or content, were significantly more likely to intend to bet in the next $24 \mathrm{hr}$, and for sports bettors, intend to bet more than those who received fewer direct messages.

In terms of direct message channel, for both groups, the number of emails received (but not texts) were positively associated with both a higher intention to bet and intention to bet larger amounts. These results remained significant when controlling for individual differences, problem gambling status, and whether it was a signature betting day (Melbourne Cup, AFL, or NRL grand final).

The results for content were less clear. For race bettors, receiving refund stake offers were associated with a lower intention to bet. This was not significant when controlling for problem gambling status and signature betting days. For sports bettors, no specific inducement types were associated with either intention to bet, or amount intended to be bet, whether controlling for problem gambling status and signature betting days or not.

\section{The relationship between direct messages and actual betting}

As noted above, a surprising result for race bettors was that lower intention to bet (lagged from the previous $24 \mathrm{hr}$ ) was associated with higher likelihood of actually betting and amount of money bet. For sports bettors, no relationship was found between intention and betting behavior (Tables 4 and 5).

For both race and sports bettors, receiving more direct messages, regardless of channel or content, was associated with greater likelihood of betting. Number of direct messages received was also positively associated with the amount of money bet for race bettors, but not sports bettors.

For both race and sports bettors, the number of texts received was positively associated with both the likelihood of actually betting and the amount bet, and this remained significant when controlling for signature betting days and problem gambling status. For sports bettors, the amount of emails received was positively associated with placing a bet, but not the amount of money bet. The number of emails was not associated with placing a bet or amount of money bet for race bettors. All relationships remained significant when controlling for signature betting days and problem gambling status.

Among race bettors, receiving more refund stake offers and bonus odds offers was related to actually placing bets in bivariate models, but not in multivariate models. The same inducements, as well as sign-up offers and match stake/ deposit offers, were positively associated with amount of money bet, but these were not significant when controlling for other factors. For sports bettors, receiving more bonus 


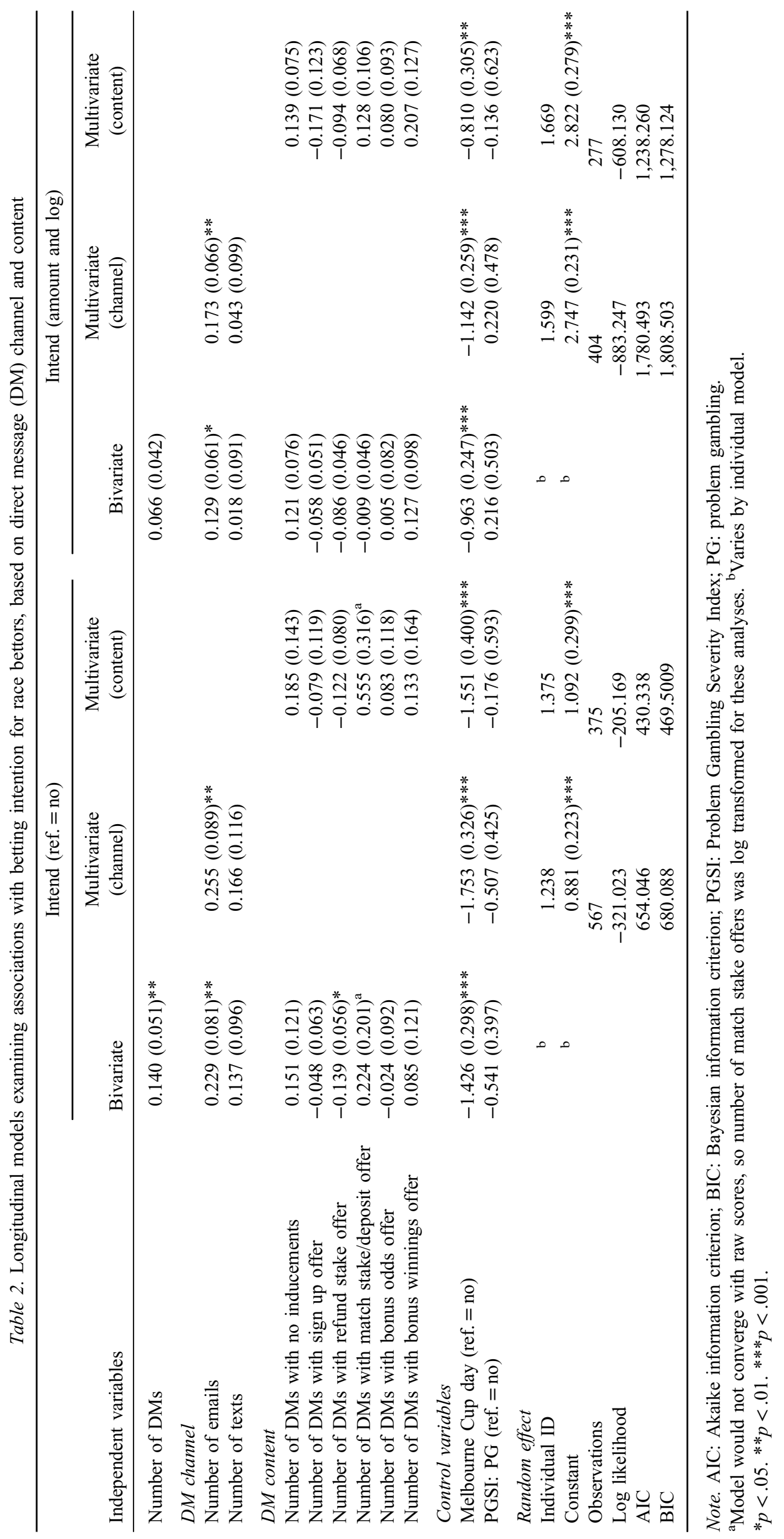


Russell et al.

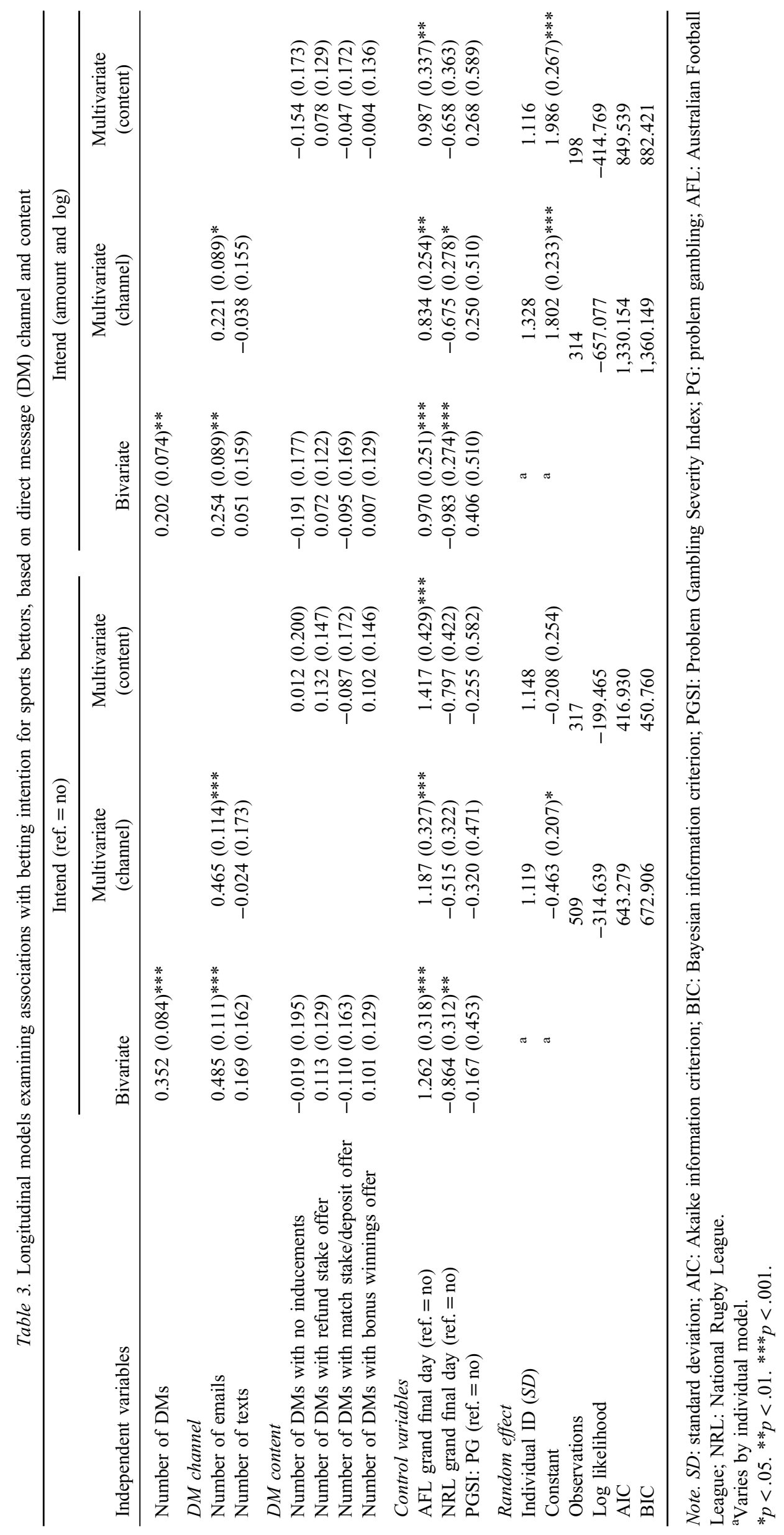




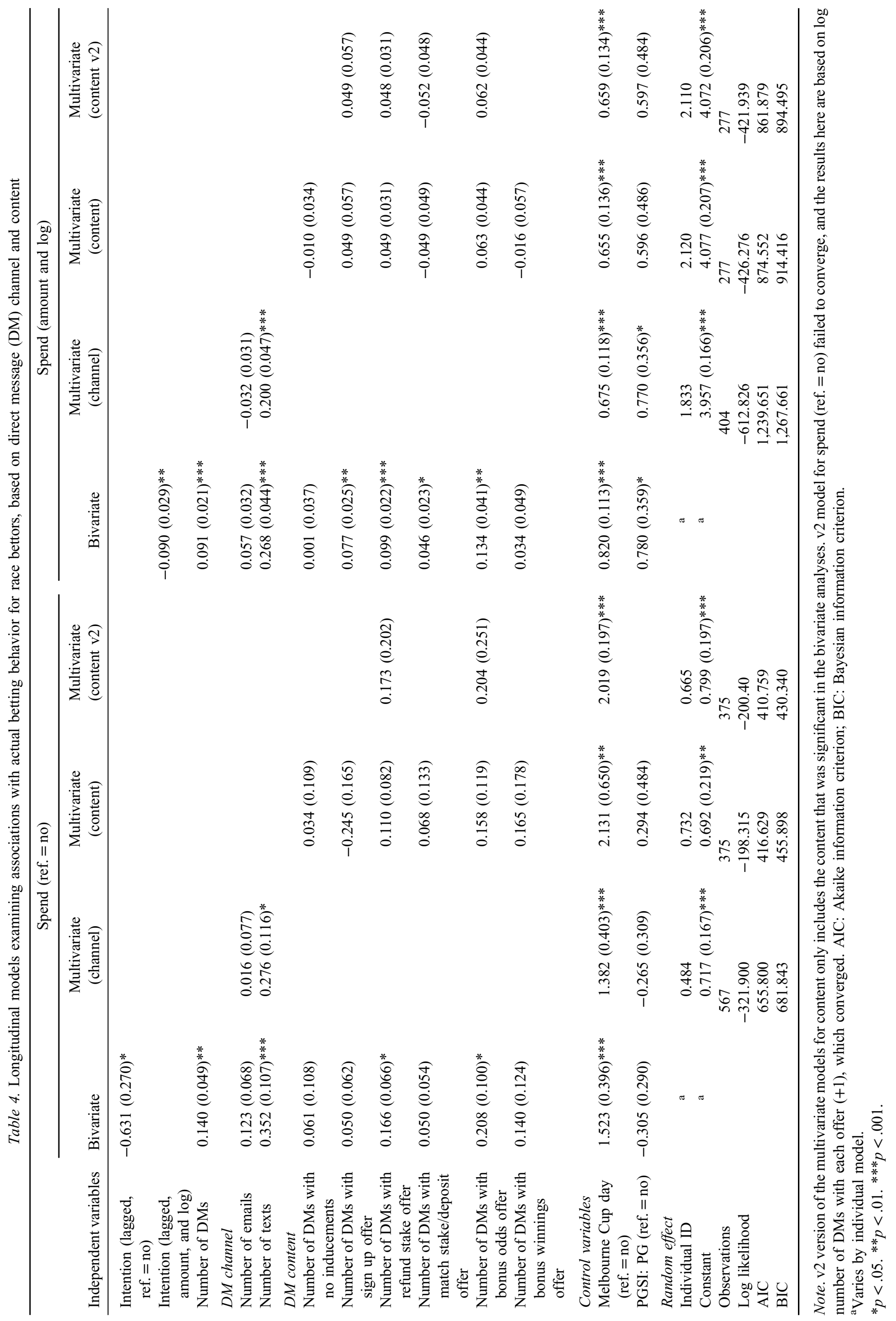


Russell et al.

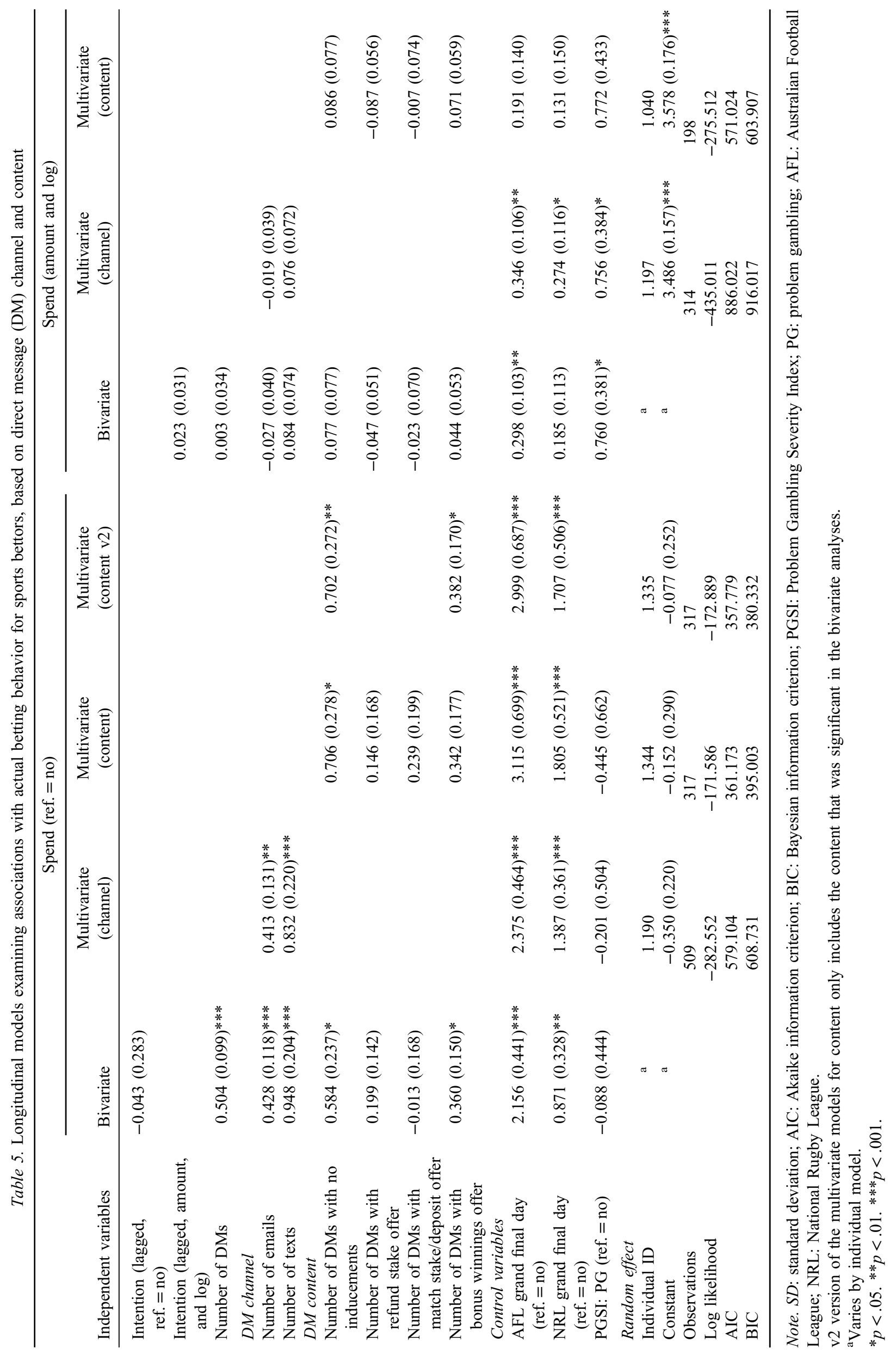


winning inducements, as well as direct messages with no inducements, was positively associated with placing a bet, and these remained significant when controlling for other factors. However, no specific inducements were associated with amount of money bet among sports bettors.

\section{DISCUSSION AND CONCLUSIONS}

The results indicate a clear relationship between direct messaging from wagering operators and both intention to bet, as well as actual betting behavior, including amount bet. This aligns with the broader literature on the effectiveness of direct messaging (Davey, 2013; Doherty, 2014; Drossos et al., 2013; Kowalke, 2014; Scharl et al., 2005; Shankar \& Balasubramanian, 2009), as well as previous findings in gambling research (Hing, Russell, Rockloff, et al., 2018). Crucially, our analysis controlled for individual variability and thus the observed effects relate to influences of direct marketing within individuals.

The channel used for direct messages is an important factor, with emails associated with intention, but texts associated with actual expenditure. This is likely related to texts having a higher open rate and faster response rate compared to emails (Davey, 2013; Fallows, 2003; Lam, 2018), making texts a particularly effective marketing tool (Scharl et al., 2005; Shankar \& Balasubramanian, 2009). The connection between texts and subsequent immediate betting behavior indicates an impulsive response to this marketing, in line with previous push-marketing findings (Unni \& Harmon, 2007). Given the relationship between impulse betting and problem gambling (Flack \& Buckby, 2018; Hing, Li, et al., 2018; Russell et al., 2018; Yan et al., 2016), we expected an interaction between problem gambling status and amount of texts received, both in terms of likelihood of betting and actual betting expenditure. The current results instead suggest that these texts prompt impulsive betting across all PGSI groups. This is concerning because impulse betting reflects impaired control and uninformed decision-making, which leads to betting more than intended (Hing, Russell, Li, \& Vitartas, 2018).

In contrast to texts, emails influenced only betting intentions. This may be because our analyses related direct messages received to gambling intention and behavior within the same $24 \mathrm{hr}$ period, and emails are not acted upon for 2.5 days on average (Davey, 2013). More cumulative effects of direct messaging on consumers are an avenue for future research (Gotlieb, Scholl, Ridout, Goldstein, \& Shah, 2017; Hing, Russell, Rockloff, et al., 2018; Houston \& Weiss, 1975; Palda, 1965).

Intention was not associated with actual betting behavior for sports bettors, and for race bettors, lower intention was associated with betting behavior. Previous gambling research (Hing, Russell, Rockloff, et al., 2018), as well as theories of planned behavior (Ajzen, 1991; Fishbein \& Ajzen, 1975), has generally found that intention predicts behavior. When an EMA methodology was used in weeks without signature betting events, intention was strongly associated with behavior (Hing, Russell, Rockloff, et al., 2018). The present finding suggests that intentions to abstain, or to bet smaller amounts, can easily be broken in these peak betting weeks. This may not be solely due to direct marketing. Other factors may be involved, including other advertising, and perceived or actual social pressure, which is a key predictor of gambling intention and behavior (Dahl, Tagler, \& Hohman, 2018; Hing, Vitartas, Lamont, \& Fink, 2014; Larimer \& Neighbors, 2003; Martin et al., 2010; Moore \& Ohtsuka, 1999; Neighbors et al., 2007), and is likely to be high around signature betting days. Because EMAs are short, we could not capture all relevant information, and note this for future research.

The relationship between inducements and intention was either not significant, or did not remain significant when controlling for problem gambling status and signature betting days. However, inducements that were associated with placing a bet were refund stake and bonus odds offers for race bettors (although not in multivariate models), and bonus winnings offers for sports bettors. These findings are generally in line with previous research (Hing, Russell, Rockloff, et al., 2018). Inducements were not associated with the amount of actual expenditure, potentially because inducements are often capped (e.g., match your deposit up to $\$ 100)$. Furthermore, the number of direct messages containing no inducements was associated with betting behavior for sports bettors and thus they may simply serve as a cue to bet. Such marketing cues have been identified as particularly powerful in progressing people along a consumption continuum, from non-use toward addiction (Martin et al., 2013).

Higher risk gamblers tend to have accounts with numerous operators (Brown, 2017; Gainsbury, 2015; Gainsbury, Russell, Blaszczynski, \& Hing, 2015; Hing, Cherney, et al., 2014). These consumers will therefore receive more direct messaging overall, further increasing their expenditure, exacerbating their gambling problems and consequent harm. Placing conservative limits on how frequently operators can message individual consumers could help protect bettors with multiple accounts. However, the private nature of direct messages makes them difficult to monitor and regulate. Another way to reduce direct messaging would be to require operators to only contact consumers who have accounts (as is the case in NSW), and who have opted-in (instead of the current opt-out system), where they would not receive direct messages unless specifically requested. Another alternative would be to establish a Do Not Direct Message register, similar to the existing Do Not Call register (Do Not Call Register Act, 2006), which would prohibit operators contacting consumers who have registered, acting as a multioperator opt-out system. Do Not Call registers are effective at reducing direct contact by industry (Sahin \& Francillon, 2018), and could help reduce harm related to direct messaging by limiting exposure.

Research into US pharmaceutical advertising has noted the difficulty of regulating direct marketing (Gibson, 2014; Henney, 2000; Mackey, 2016; Taylor, Franke, \& Maynard, 2000). Gibson (2014) concluded that third party oversight and industry self-regulation are important in regulating direct marketing, although gambling industry self-regulation has been criticized (Selin, 2016). A complementary approach is consumer education, which does not aim to remove the onus of responsibility from industry, but instead empowers consumers to make informed decisions around their gambling 
behavior (Hing, Russell, \& Hronis, 2016; Martin et al., 2013). For example, consumers could be educated about ways to minimize or eliminate direct messaging (e.g., opting out), or how to resist urges to bet impulsively when such messages are received. Consumers could also be educated about when messages breach standards, and how to report them if they do.

\section{Limitations and strengths}

The limitations of this study include not all direct messages received were forwarded to the research team; the relatively small sample of respondents (due to budget constraints); that expenditure and intention were self-reported; not all relevant variables could be captured in the short EMA surveys; and that the relationship between receiving direct messages and expenditure or intention were for a $24-\mathrm{hr}$ window. The latter limitation meant that more cumulative advertising or inducement influences were not captured in the present analyses. While the present design aims to reduce recall bias and subjectivity (evidenced by the researchers coding message content), causation cannot be inferred from these results.

Despite these limitations, this study has the following strengths: daily surveys reduced recall bias, particularly for expenditure; intention to bet and subsequent actual expenditure could be compared; a longitudinal analysis that had the power to find these significant effects and minimize bias due to missingness; and the capture and analysis of the content of actual direct messages sent to consumers. On the whole, the methodology provides a robust measurement and analysis of betting intention, actual betting behavior, and exposure to direct messaging.

\section{CONCLUSIONS}

The results from this study confirm that direct messages are influential on betting behavior, with participants betting even when not intending to do so, even when controlling for individual differences, PGSI status, and major betting days. The most influential direct message factor was receiving direct messages via text. Particularly, betting based on texts is likely to be unplanned and impulsive in nature, which is a concern because this is a known risk factor for problem gambling and gambling-related harm. As such, direct messages are an effective but also potentially harmful marketing tool.

Funding sources: This study was funded by the Victorian Responsible Gambling Foundation, as an extension of another project entitled "Effects of wagering marketing on vulnerable adults."

Authors' contribution: AMTR, NH, and VR designed the study, the surveys, and conducted data collection. AMTR wrote the first draft of all sections of the manuscript, and conducted the statistical analyses, based on analyses conducted by MB for the original project on effects of wagering marketing. MB provided guidance and troubleshooting for the present analyses. NH led the overall project and provided guidance on "Introduction" and "Discussion" sections. VR conducted the content analysis of the direct messages. All authors read and commented on the manuscript and approved it for submission.

Conflict of interest: AMTR has received funding from Victorian Responsible Gambling Foundation; Queensland Justice and Attorney-General; Gambling Research Australia; National Association for Gambling Studies; Australian Communications and Media Authority and the Alberta Gambling Research Institute. He has received industry funding for an evaluation of problem gambling among casino employees from Echo/Star Entertainment Group. He is also affiliated with the University of Sydney. He declares no conflict of interest in relation to this manuscript. $\mathrm{NH}$ has received research funds from the Victorian Responsible Gambling Foundation, Gambling Research Australia, Australian Government Department of Social Services, Alberta Gambling Research Institute, the Australian Gambling Research Centre, the Queensland, New South Wales, Victorian and South Australian Governments, the Australian Research Council, and Australia's National Research Organisation for Women's Safety. She has also received consultancy funds from Echo Entertainment and Sportsbet and an honorarium from Singapore Pools for membership of its International Advisory Committee. She declares that she has no conflict of interest in relation to this manuscript. $\mathrm{MB}$ has received research funds from the Victorian Responsible Gambling Foundation, Queensland Government Department of Health, Australian Department of Social Services, New Zealand Ministry of Health, Department of Families, Housing, Community Services and Indigenous Affairs, Department of Innovation, Industry, Science and Research, Australian Department of Foreign Affairs and Trade, Japanese Ministry of Economy, Trade and Industry. He declares no conflicts of interest in relation to this manuscript. VR declares no conflict of interest in relation to this manuscript.

\section{REFERENCES}

Ajzen, I. (1991). The theory of planned behavior. Organizational Behavior and Human Decision Processes, 50(2), 179-211. doi:10.1016/0749-5978(91)90020-T

Australian Communication and Media Authority. (2013). Betting odds and advertising for betting agencies during sports. Canberra, Australia: Australian Communication and Media Authority. Retrieved from http://www.acma.gov.au/ /media/ mediacomms/Report/pdf/Community_attitudes_to_live_odds_ and_sport_pdf $1 \% 20$ pdf.pdf

Bates, D., Mächler, M., Bolker, B., \& Walker, S. (2015). Fitting linear mixed-effects models using lme4. Journal of Statistical Software, 67(1), 1-48. doi:10.18637/jss.v067.i01

Brown, T. (2017). Online gambling: Problem gamblers and the multi-operator self exclusion scheme. UK House of Lords. Retrieved from http://researchbriefings.files.parliament.uk/ documents/LLN-2017-0082/LLN-2017-0082.pdf

Chaffey, D. (2018). Email marketing engagement and response statistics 2018. Retrieved from https://www.smartinsights.com/ 
email-marketing/email-communications-strategy/statisticssources-for-email-marketing/

Dahl, E., Tagler, M. J., \& Hohman, Z. P. (2018). Gambling and the reasoned action model: Predicting past behavior, intentions, and future behavior. Journal of Gambling Studies, 34(1), 101-118. doi:10.1007/s10899-017-9702-6

Davey, N. (2013). SMS marketing campaigns. Retrieved from https://www.smartinsights.com/mobile-marketing/smsmarketing-campaigns/

Deloitte. (2017). Mobile consumer survey 2017. Retrieved from http://landing.deloitte.com.au/rs/761-IBL-328/images/tmtmobile-consumer-survey-2017_pdf.pdf

Department of Broadband, Communications and the Digital Economy. (2013). Review of the Interactive Gambling Act 2001 - Final report 2012. Canberra, Australia: Department of Broadband, Communications and the Digital Economy.

Doherty, A. (2014). SMS versus email marketing. Retrieved from https://www.business2community.com/digital-marketing/smsversus-email-marketing-0957139

Do Not Call Register Act. (2006). Federal register of legislation. Retrieved from https://www.legislation.gov.au/Series/C2006 A00088

Drossos, D. A., Giaglis, G. M., Vlachos, P. A., Zamani, E. D., \& Lekakos, G. (2013). Consumer responses to SMS advertising: Antecedents and consequences. International Journal of Electronic Commerce, 18(1), 105-136. doi:10.2753/JEC10864415180104

Fallows, D. (2003). Spam: How it is hurting email and degrading life on the Internet. Washington, DC: Pew Internet. Retrieved from http://www.pewinternet.org/files/old-media/Files/Reports/ 2003/PIP_Spam_Report.pdf.pdf

Ferris, J. A., \& Wynne, H. J. (2001). The Canadian Problem Gambling Index: Final report. Ottawa, Canada: Canadian Centre on Substance Abuse.

Fishbein, M., \& Ajzen, I. (1975). Belief, attitude, intention, and behavior: An introduction to theory and research. Reading, MA: Addison-Wesley.

Flack, M., \& Buckby, B. (2018). Impulsivity and problem gambling: Can the anticipated emotional rewards explain the relationship? International Journal of Mental Health and Addiction. Advance online publication. doi:10.1007/s11469018-9950-4

Gainsbury, S. M. (2012). Internet gambling: Current research findings and implications. New York, NY: Springer.

Gainsbury, S. M. (2015). Online gambling addiction: The relationship between Internet gambling and disordered gambling. Current Addiction Reports, 2(2), 185-193. doi:10.1007/ S40429-015-0057-8

Gainsbury, S. M., Russell, A., Blaszczynski, A., \& Hing, N. (2015). Greater involvement and diversity of Internet gambling as a risk factor for problem gambling. European Journal of Public Health, 25(4), 723-728. doi:10.1093/eurpub/ ckv006

Gibson, S. (2014). Regulating direct-to-consumer advertising of prescription drugs in the digital age. Laws, 3(3), 410-438. doi: 10.3390/laws3030410

Gotlieb, M. R., Scholl, R. M., Ridout, T. N., Goldstein, K. M., \& Shah, D. V. (2017). Cumulative and long-term campaign advertising effects on trust and talk. International Journal of Public Opinion Research, 29(1), 1-22. doi:10.1093/ijpor/ edv047
Guerrero-Solé, F., Lopez-Gonzalez, H., \& Griffiths, M. D. (2017). Online gambling advertising and the third-person effect: A pilot study. International Journal of Cyber Behavior, Psychology and Learning, 7(2), 15-30. doi:10.4018/IJCBPL. 2017040102

H2 Gambling Capital. (2017). Global gambling losses. Retrieved from http://h2gc.com/

Henney, J. E. (2000). Challenges in regulating direct-to-consumer advertising. JAMA, 284(17), 2242. doi:10.1001/jama.284. 17.2242-JMS1101-3-1

Hing, N., Cherney, L., Blaszczynski, A., Gainsbury, S. M., \& Lubman, D. I. (2014). Do advertising and promotions for online gambling increase gambling consumption? An exploratory study. International Gambling Studies, 14(3), 394-409. doi:10.1080/14459795.2014.903989

Hing, N., Gainsbury, S. M., Blaszczynski, A., Wood, R., Lubman, D., \& Russell, A. M. T. (2014). Interactive gambling. Melbourne, Australia: Gambling Research Australia.

Hing, N., Li, E., Vitartas, P., \& Russell, A. M. T. (2018). On the spur of the moment: Intrinsic predictors of impulse sports betting. Journal of Gambling Studies, 34(2), 413-428. doi:10.1007/s10899-017-9719-x

Hing, N., Russell, A. M. T., \& Hronis, A. (2016). Behavioural indicators of responsible gambling consumption. Melbourne, Australia: Victorian Responsible Gambling Foundation.

Hing, N., Russell, A. M. T., Li, E., \& Vitartas, P. (2018). Does the uptake of wagering inducements predict impulse betting on sport? Journal of Behavioral Addictions, 7(1), 146-157. doi:10.1556/2006.7.2018.17

Hing, N., Russell, A. M. T., Rockloff, M. J., Browne, M., Langham, E., Li, E., Lole, L., Greer, N., Thomas, A., Jenkinson, R., Rawat, V., \& Thorne, H. (2018). Effects of wagering marketing on vulnerable adults. Melbourne, Australia: Victorian Responsible Gambling Foundation.

Hing, N., Russell, A. M. T., Vitartas, P., \& Lamont, M. (2016). Demographic, behavioural and normative risk factors for gambling problems amongst sports bettors. Journal of Gambling Studies, 32(2), 625-641. doi:10.1007/s10899015-9571-9

Hing, N., Sproston, K., Brading, R., \& Brook, K. (2015). Review and analysis of sports and race betting inducements. Melbourne, Australia: Victorian Responsible Gambling Foundation.

Hing, N., Vitartas, P., Lamont, M., \& Fink, E. (2014). Adolescent exposure to gambling promotions during televised sport: An exploratory study of links with gambling intentions. International Gambling Studies, 14(3), 374-393. doi:10.1080/ 14459795.2014.902489

Houston, F. S., \& Weiss, D. L. (1975). Cumulative advertising effects: The role of serial correlation. Decision Sciences, 6(3), 471-481. doi:10.1111/j.1540-5915.1975.tb01036.x

Joint Select Committee on Gambling Reform. (2011). Interactive and online gambling and gambling advertising. Canberra, Australia: Commonwealth of Australia.

Joint Select Committee on Gambling Reform. (2013). The advertising and promotion of gambling services in sport. Canberra, Australia: Commonwealth of Australia.

Kowalke, M. (2014). Text messaging might be the best marketing vehicle in 2014. Retrieved from http://technews.tmcnet.com/ channels/textmessagingresource/articles/371821-text-messagingmight-be-best-marketing-vehicle-2014.htm 
Lam, C. (2018). The 2018 updated Australian data on SMS open rates. Retrieved from https://www.esendex.com.au/blog/post/ the-2018-updated-australian-data-on-sms-open-rates/

Larimer, M. E., \& Neighbors, C. (2003). Normative misperception and the impact of descriptive and injunctive norms on college student gambling. Psychology of Addictive Behaviors, 17(3), 235-243. doi:10.1037/0893-164X.17.3.235

Lopez-Gonzalez, H., Estévez, A., \& Griffiths, M. D. (2017). Marketing and advertising online sports betting: A problem gambling perspective. Journal of Sport \& Social Issues, 41(3), 256-272. doi:10.1177/0193723517705545

Lopez-Gonzalez, H., Estévez, A., \& Griffiths, M. D. (2018). Controlling the illusion of control: A grounded theory of sports betting advertising in the UK. International Gambling Studies, 18(1), 39-55. doi:10.1080/14459795.2017.1377747

Lopez-Gonzalez, H., \& Griffiths, M. D. (2017). "Cashing out" in sports betting: Implications for problem gambling and regulation. Gaming Law Review, 21(4), 323-326. doi:10.1089/ glr2.2017.2144

Lopez-Gonzalez, H., Guerrero-Solé, F., \& Griffiths, M. D. (2018). A content analysis of how "normal" sports betting behaviour is represented in gambling advertising. Addiction Research \& Theory, 26(3), 238-247. doi:10.1080/16066359.2017. 1353082

Mackey, T. K. (2016). Digital direct-to-consumer advertising: A perfect storm of rapid evolution and stagnant regulation. Comment on "Trouble spots in online direct-to-consumer prescription drug promotion: A content analysis of FDA warning letters". International Journal of Health Policy and Management, 5(4), 271-274. doi:10.15171/ijhpm.2016.11

Martin, I. M., Kamins, M. A., Pirouz, D. M., Davis, S. W., Haws, K. L., Mirabito, A. M., Mukherjee, S., Rapp, J. M., \& Grover, A. (2013). On the road to addiction: The facilitative and preventive roles of marketing cues. Journal of Business Research, 66(8), 1219-1226. doi:10.1016/j.jbusres.2012.08.015

Martin, R. J., Usdan, S., Nelson, S., Umstattd, M. R., Laplante, D., Perko, M., \& Shaffer, H. (2010). Using the theory of planned behavior to predict gambling behavior. Psychology of Addictive Behaviors, 24(1), 89-97. doi:10.1037/a0018452

Moore, S., \& Ohtsuka, K. (1999). The prediction of gambling behavior and problem gambling from attitudes and perceived norms. Social Behavior and Personality, 27(5), 455-466. doi:10.2224/sbp.1999.27.5.455

Neighbors, C., Lostutter, T. W., Whiteside, U., Fossos, N., Walker, D. D., \& Larimer, M. E. (2007). Injunctive norms and problem gambling among college students. Journal of Gambling Studies, 23(3), 259-273. doi:10.1007/s10899-007-9059-3

New South Wales Department of Industry: Liquor and Gaming [NSW DILG]. (2015). Publication of gambling advertising. Retrieved from https://www.liquorandgaming.nsw.gov.au/ Pages/about-us/news-and-media/recent-news/publication-ofgambling-advertising.aspx

New South Wales Department of Industry: Liquor and Gaming [NSW DILG]. (2016). Publication of gambling advertising. Retrieved from https:/www.liquorandgaming.nsw.gov.au/ Documents/gaming-and-wagering/wagering-applications/fs3048publication-of-gambling-advertising.pdf

New South Wales Department of Industry: Liquor and Gaming [NSW DILG]. (2018). Gambling advertising and inducements. Retrieved from https://www.liquorandgaming.nsw.gov.au/
Documents/gaming-and-wagering/law-and-policy/GW5551_ GL4015_Publication\%20of\%20gambling\%20advertising_ guidelines_Final.pdf

O'Farrell, B. (2015). Review of illegal offshore wagering. Canberra, Australia: Department of Social Services, Commonwealth of Australia.

Palda, K. S. (1965). The measurement of cumulative advertising effects. The Journal of Business, 38(2), 162-179. doi:10.1086/ 294759

Pitt, H., Thomas, S. L., Bestman, A., Daube, M., \& Derevensky, J. (2017). What do children observe and learn from televised sports betting advertisements? A qualitative study among Australian children. Australian and New Zealand Journal of Public Health, 41(6), 604-610. doi:10.1111/1753-6405.12728

Queensland Government Statisticians Office. (2017). Australian gambling statistics 1990-91 to 2015-16 (33rd ed.). Brisbane, Australia: Queensland Government Statisticians Office Retrieved from http://www.qgso.qld.gov.au/products/reports/ aus-gambling-stats/aus-gambling-stats-33rd-edn.pdf

R Core Team. (2017). R: A language and environment for statistical computing. Vienna, Austria: R Foundation for Statistical Computing. Retrieved from https://www.R-project.org/

Roy Morgan. (2018). Mobile betting drives growth in online wagering. Retrieved from https://www.roymorgan.com/ findings/7624-mobile-betting-users-march-2018-201806172313

Russell, A. M. T., Hing, N., Li, E., \& Vitartas, P. (2018). Gambling risk groups are not all the same: Risk factors amongst sports bettors. Journal of Gambling Studies. Advance online publication. doi:10.1007/s10899-018-9765-z

Sahin, M., \& Francillon, A. (2018). On the effectiveness of the national do-not-call registries. San Fransisco, CA: IEEE. Retrieved from http://www.eurecom.fr/publication/5530

Scharl, A., Dickinger, A., \& Murphy, J. (2005). Diffusion and success factors of mobile marketing. Electronic Commerce Research and Applications, 4(2), 159-173. doi:10.1016/j. elerap.2004.10.006

Selin, J. (2016). From self-regulation to regulation - An analysis of gambling policy reform in Finland. Addiction Research \& Theory, 24(3), 199-208. doi:10.3109/16066359.2015.1102894

Shankar, V., \& Balasubramanian, S. (2009). Mobile marketing: A synthesis and prognosis. Journal of Interactive Marketing, 23(2), 118-129. doi:10.1016/j.intmar.2009.02.002

Sproston, K., Hanley, C., Brook, K., Hing, N., \& Gainsbury, S. M. (2015). Marketing of sports betting and racing. Melbourne, Australia: Gambling Research Australia.

Stone, A. A., \& Shiffman, S. (1994). Ecological momentary assessment (EMA) in behavioral medicine. Annals of Behavioral Medicine, 16(3), 199-202. doi:10.1093/abm/16.3.199

Taylor, C. R., Franke, G. R., \& Maynard, M. L. (2000). Attitudes toward direct marketing and its regulation: A comparison of the United States and Japan. Journal of Public Policy \& Marketing, 19(2), 228-237. doi:10.1509/jppm.19.2.228.17127

Unni, R., \& Harmon, R. (2007). Perceived effectiveness of push vs. pull mobile location based advertising. Journal of Interactive Advertising, $\quad 7(2), \quad 28-40 . \quad$ doi:10.1080/15252019.2007. 10722129

Yan, W.-S., Zhang, R.-R., Lan, Y., Li, Y.-H., \& Sui, N. (2016). Comparison of impulsivity in non-problem, at-risk and problem gamblers. Scientific Reports, 6(1), 39233. doi:10.1038/ srep39233 